\title{
Impact of a non-restrictive satiating diet on anthropometrics, satiety responsiveness and eating behaviour traits in obese men displaying a high or a low satiety phenotype
}

\author{
Hélène Arguin ${ }^{1}$, Angelo Tremblay ${ }^{1,2,3}$, John E. Blundell ${ }^{4}$, Jean-Pierre Després ${ }^{1,2}$, Denis Richard ${ }^{2}$, \\ Benoit Lamarche ${ }^{3}$ and Vicky Drapeau ${ }^{2,3,5 *}$ \\ ${ }^{1}$ Department of Kinesiology, Faculty of Medicine, Laval University, Quebec, QC, Canada, G1V OA6 \\ ${ }^{2}$ Quebec Heart and Lung Institute/Research Center, Quebec, QC, Canada, G1V $4 G 5$ \\ ${ }^{3}$ Institute of Nutraceuticals and Functional Foods, Laval University, Quebec, QC, Canada, G1V OAC \\ ${ }^{4}$ Biopsychology Group, Institute of Psychological Sciences, University of Leeds, Leeds LS2 9JZ, UK \\ ${ }^{5}$ Department of Physical Education, Faculty of Education, Laval University, Quebec, QC, Canada, G1V OA6 \\ (Submitted 3 May 2017 - Final revision received 1 August 2017 - Accepted 18 August 2017)
}

\section{Abstract}

The aim of this study was to evaluate the impact of a non-restrictive satiating diet in men displaying various degrees of satiety efficiency. In all, sixty-nine obese men aged 41.5 (SD 5.7) years were randomly assigned to a control (10-15, 55-60 and 30\% energy as protein, carbohydrate and lipid, respectively; $n$ 34) or satiating (20-25, 45-50 and 30-35\% energy as protein, carbohydrate and lipid, respectively; $n 35)$ diet for 16 weeks, and were classified as having a low (LSP) or high (HSP) satiety phenotype. Both diets were consumed ad libitum. Changes in body weight, BMI, percent fat mass, waist circumference, satiety responsiveness and eating behaviour traits were assessed following the intervention. Dropout rates were higher in the control diet (44.1\%) compared with the satiating diet (8.6\%). Decreases in body weight, BMI and waist circumference were significant in both groups, yet HSP individuals lost more body weight than LSP individuals $(P=0 \cdot 048)$. Decreases in \% fat mass were greater in the satiating diet (LSP: $-2 \cdot 1$ (sD 2.1$) \% ; P<0.01$ and HSP: -3.0 (sD 2.5 ) \%; $P<0.001$ ) compared with the control diet (LSP: -1.1 (sD 2.5$) \%$ and HSP: -1.3 (sD 2.6$) \%$ ) ( $P=0.034$ ). Satiety responsiveness was markedly improved in the satiating diet, whereas no significant changes were observed in the control group. Changes in dietary restraint ( $+3 \cdot 3$ (sD $2 \cdot 9)$ to $+7 \cdot 2$ (SD $5 \cdot 5$ )), flexible control $(+0.9$ (sD 1.4) to +2.3 (sD 2.7)), rigid control ( +2.2 (sD 1.5) to +2.5 (sD 2.8)), disinhibition ( -2.8 (sD 3.7) to -3.2 (sD 2.6 )) and susceptibility to hunger $(-2.7$ (SD $4 \cdot 1)$ to -4.6 (sD 3.9)) were similar between the diets. Compared with the control diet, the satiating diet favoured adherence, decreased \% fat mass and improved satiety responsiveness in both HSP and LSP individuals.

Key words: Non-restrictive diets: Weight loss: Appetite control: Eating behaviours: Satiety responsiveness: Satiety phenotypes: Satiety quotients

Obesity is a multifactorial condition that can lead to serious health problems. It develops from complex interactions between a wide array of environmental and genetic factors, and marked individual aetiological differences justify the use of personalised interventions to prevent and treat obesity.

The control of food intake and energy balance implies a dynamic interaction between biological/physiological and behavioural/psychological factors ${ }^{(1)}$. Satiation and post-ingestive satiety efficiency vary greatly between individuals. Studies show that some individuals (both non-obese and obese) have difficulty to recognise their appetite sensations before and after a substantial energetic load ${ }^{(2)}$. This 'low satiety phenotype' (LSP) has been observed in approximately $10 \%$ of obese patients consulting for weight loss in our nutrition clinic ${ }^{(3)}$, and has been associated with higher reported and measured energy intakes ${ }^{(4,5)}$. LSP individuals are characterised by a difficulty to detect changes in their appetite sensations throughout the day, a weak satiety response to a meal, and in some cases by an increase in appetite after a meal ${ }^{(2,6)}$. In one study, higher disinhibition scores from the Three-Factor Eating Questionnaire (TFEQ), an eating behaviour trait that indicates a higher susceptibility for overconsumption on a regular basis, were also reported ${ }^{(2)}$. Consequently, it has been hypothesised that the LSP individuals could be more vulnerable to weight gain and resistance to weight loss ${ }^{(6)}$.

Energy restriction remains largely used as the obvious approach to induce weight loss in the management of obesity.

Abbreviations: HSP, high satiety phenotype; LSP, low satiety phenotype; PFC, prospective food consumption; SQ, satiety quotient; TEFQ, Three-Factor Eating Questionnaire; VAS, visual analogous scale.

* Corresponding author: V. Drapeau, fax +1 418656 2441, email vicky.drapeau@fse.ulaval.ca 
However, there is ample evidence to suggest that the long-term effects of energy-restricted diets on body weight in individuals with obesity is at best modest, and long-term weight regain is observed in the majority of individuals ${ }^{(7)}$. This can be explained, in part, by some negative effects on appetite control that result from fat mass loss, such as an increase in hunger and desire to eat ${ }^{(8)}$. Thus, there is a need to study weight control strategies that promote a spontaneous energy deficit without significantly altering hunger and satiety levels and that take into account individual differences in satiety responsiveness. One promising alternative could be the combination of multiple functional foods that are known for their satiety-enhancing properties in order to develop a 'highly satiating', healthy and non-restrictive diet, that could be maintained over the long term. Food properties or functional agents that may influence satiation and satiety and/or create a spontaneous decrease in energy intake include low energy density ${ }^{(9)}$, and a higher content of protein $(>20 \% \text { of energy from protein })^{(10,11)}$, dietary fibre ${ }^{(12)}$, long-chain $n-3$ fatty acids ${ }^{(13)}$, dietary $\mathrm{Ca}^{(14)}$ and capsaicinoids $^{(15)}$.

Even though these food-related factors have been shown to help short-term appetite control under standardised laboratory conditions, it is unclear whether their combination could benefit obese individuals, including those who express low satiety responsiveness, during the weight loss process. The objective of this study was to evaluate the impact of a non-restrictive (ad libitum), highly satiating diet on body weight and composition, satiety responsiveness, eating behaviour traits and adherence in obese men displaying large variations in their satiety efficiency. We hypothesised that, compared with a nonrestrictive conventional dietary plan based on the Canadian Food Guide ${ }^{(16)}$, the highly satiating diet would result in greater decreases in body weight and fat mass, a better satiety responsiveness, more desirable changes in eating behaviour traits and a higher adherence rate in individuals characterised by low or high satiety responsiveness.

\section{Methods}

\section{Participants}

In all, seventy-five men were recruited through physicians and media from the Quebec City area. Eligibility of the participants was first determined by a telephone interview. Inclusion criteria were: aged between 30 and 50 years, obese (BMI between 30 and $40 \mathrm{~kg} / \mathrm{m}^{2}$ ), overall good health, no medications which could influence appetite sensations (hormones, tranquilisers such as chlorpromazine and benzodiazepin, lithium carbonate, ciproheptadin, antihistaminic, serotonin antagonist, sulfonylurea and glucocorticoids), no body weight variations of more than $4 \mathrm{~kg}$ over the last 2 months, and being sedentary to moderately active (i.e. participating in moderate to vigorous physical activity $\leq 3 \times 30 \mathrm{~min} /$ week). Eligible participants were then invited to a screening visit to confirm the inclusion criteria and to present the details of the project. Dietary restriction was also assessed at the screening visit with the use of the TFEQ ${ }^{(17)}$ and restrained participants (i.e. cognitive restraint score $>10$ ) were excluded. After the screening session, six participants were excluded (three for high fasting glucose/diabetes, one for high TAG, one for hypothyroidism and one for lack of motivation). The remaining sixty-nine participants were selected to participate in the study. This study was conducted according to the guidelines laid down in the Declaration of Helsinki and all procedures involving human subjects were approved by the Laval University Ethics Committee in Health Sciences and the Quebec Heart and Lung Institute/Research Center Ethic Committee (protocol record MOP-68858). Written informed consent was obtained from all subjects. Trial registration no.: NCT03128697 (https://clinicaltrials.gov).

\section{Experimental design}

The study design consisted of two phases (weight stabilisation and weight loss) and three experimental visits (V): satiety efficiency categorisation (V1), baseline measurements (V2) and post-study measurements (V3) (Fig. 1). After the weight stabilisation phase and baseline measurements (V2), participants ( $n$ 69) were randomly assigned to either an ad libitum experimental diet ( $n$ 35) or ad libitum control diet ( $n$ 34) for a 16-week period.

Satiety efficiency categorisation (V1). Participants arrived at the laboratory at 08.00 hours following a 12-h overnight fast and were invited to consume a standardised breakfast to evaluate their appetite sensations and determine the satiety quotient (SQ) for each appetite sensation. They had been instructed not to consume alcohol or engage in structured physical activity for at least $24 \mathrm{~h}$ before testing. The breakfast test meal consisted of white bread, butter, peanut butter, Cheddar cheese and orange juice, and had to be eaten within a 20 -min period. The meal was

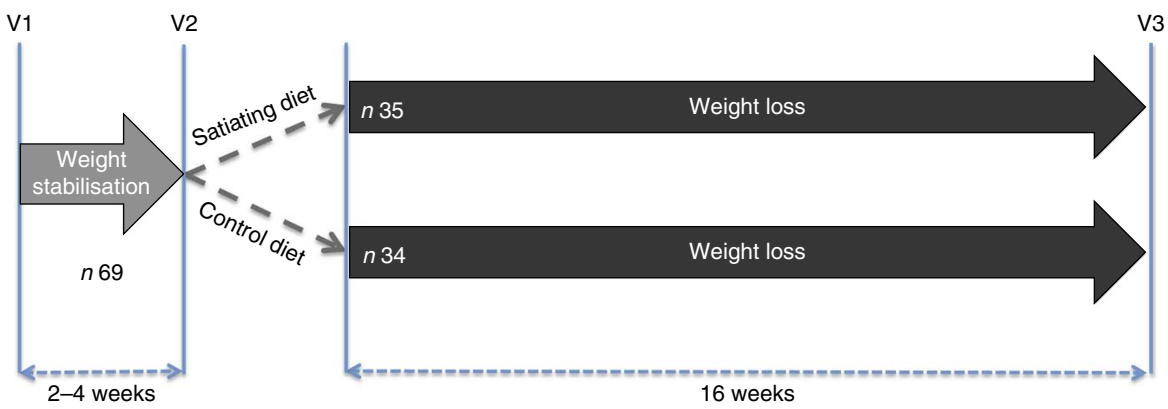

Fig. 1. Experimental design. V1, satiety efficiency categorisation; V2, baseline measurements; V3, post-tests. 
designed to provide 14, 42 and $44 \%$ of total energy as protein, fat and carbohydrate, respectively, and an energy content of $3067 \mathrm{~kJ}(733 \mathrm{kcal})$. Appetite sensations (desire to eat, hunger, fullness and prospective food consumption (PFC)) were assessed by $150 \mathrm{~mm}$ visual analogous scales (VAS) adapted from Hill \& Blundell ${ }^{(18)}$, before, immediately after and at $10 \mathrm{~min}$ intervals until $1 \mathrm{~h}$ after the breakfast. The last two VAS measurements were performed 90 and $120 \mathrm{~min}$ after the breakfast. The following questions were asked on the VAS: (1) How strong is your desire to eat? ('very weak' to 'very strong'), (2) How hungry do you feel? ('not hungry at all' to 'as hungry as I have ever felt'), (3) How full do you feel? ('not full at all' to 'very full'), and (4) How much food do you think you could eat? ('nothing at all' to 'a large amount'). VAS measurements were always performed in the same environment (i.e. alone in a quiet room, at the same table, in the same room with the same lighting that was kept free of odours and sounds as well as other potentially confounding factors (visual stimuli, individuals in the room, etc.)). Under these conditions, VAS measurements in our laboratory have been shown to be highly reliable both before and in response to a meal ${ }^{(19)}$. The satiety efficiency of each individual (referred to as the SQ for desire to eat, hunger, fullness and PFC as well as the mean SQ) was calculated with the following equation ${ }^{(4)}$ :

\section{$\mathrm{SQ}(\mathrm{mm} / 418 \mathrm{~kJ}(100 \mathrm{kcal}))$}

$$
=\frac{\left(\begin{array}{c}
\text { fasting appetite sensations }(\mathrm{mm})-\text { mean of the } \\
60 \text {-min post-meal appetite sensations }(\mathrm{mm})
\end{array}\right)}{\text { energy content of the test meal }(\mathrm{kJ}(\mathrm{kcal}))} \times 100 \text {. }
$$

It is important to note that the SQ calculation for fullness is reversed (the mean post-meal rating - fasting rating). The theoretical range of possible SQ values is between -20.5 and 20.5 $\mathrm{mm} / 418 \mathrm{~kJ}(100 \mathrm{kcal})$. A higher SQ for each of the appetite sensations represents a stronger appetite response to ingested food whereas a lower SQ represents a weaker response.

The low satiety phenotype. The mean of the SQ (mean SQ) for the four different appetite sensations was used to classify the participants according to their individual satiety efficiency (high $v$. low). Individuals with a mean $\mathrm{SQ}<8 \mathrm{~mm} / 418 \mathrm{~kJ}$ (100 kcal) were classified as having a low appetite response to a meal (i.e. the LSP), whereas those with an SQ $\geq 8 \mathrm{~mm} / 418 \mathrm{~kJ}$ (100 kcal) were classified as the high satiety phenotype (HSP), as previously described $^{(6)}$. The reliability of the SQ as a marker of satiety efficiency has been demonstrated under controlled laboratory conditions in men ${ }^{(6)}$ and women ${ }^{(20)}$.

Weight stabilisation phase. After the first experimental visit (V1), participants were instructed to keep their weight and lifestyle stable for the next 2-4 weeks.

Baseline measurements (V2). After the weight stabilisation phase, participants returned to the laboratory for a second experimental visit (V2). They arrived at the laboratory at 08.00 hours following a 12-h overnight fast and had been instructed not to consume alcohol or engage in structured physical activity for at least $24 \mathrm{~h}$ before testing.
Anthropometric and body composition measurements. Upon arrival, height and waist circumference were measured according to standardised procedures ${ }^{(21)}$, and body weight and composition (fat mass, lean body mass and percent fat mass) were measured by dual-energy X-ray absorptiometry (DXA; GE Medical Systems Lunar). BMI was calculated as DXA body weight divided by height squared $\left(\mathrm{kg} / \mathrm{m}^{2}\right)$. Of note, for each DXA measurement, participants arrived in the same condition (i.e. being fasted, rested and well-hydrated).

Eating behaviour traits assessment. Participants completed a French version of the fifty-one-item TFEQ ${ }^{(17)}$. This questionnaire measures the three following dimensions of human eating behaviours: cognitive dietary restraint (intent to control food intake), disinhibition (overconsumption of food in response to cognitive or emotional cues) and susceptibility to hunger (food intake in response to feelings and perceptions of hunger). It is also possible to distinguish two types of cognitive dietary restraint behaviours: flexible control and rigid control of eating ${ }^{(22)}$. The TFEQ is a reproducible and valid tool ${ }^{(17,23)}$ and the French version has been previously validated $^{(24)}$.

Satiety responsiveness measurement. A standardised breakfast was served at 08.30 hours (see the 'Satiety efficiency categorization (V1)' for a complete description of the procedure). The purpose of this standardised breakfast was to assess the baseline satiety responsiveness of participants (SQ for desire to eat, hunger, fullness, PFC as well as the mean SQ).

\section{Weight loss phase}

Dietary interventions. No energetic restriction was prescribed in either of the diets. The experimental diet was designed to be highly satiating and induce a spontaneous energy deficit. This diet was characterised as follows: low energy density, high micronutrient density, particularly Ca, moderate in fat (30-35\% of total energy intake, mainly PUFA), high in fibre ( $>25 \mathrm{~g} / \mathrm{d})$, high in protein (20-25\% of total energy intake) and included $45-50 \%$ energy as carbohydrate mainly provided by nonprocessed foods with a low glycaemic index (Table 1). Participants received a specific listing of highly satiating foods in order to help them with their food choices (Table 2). They were instructed to choose the majority of their daily food items from this food list. In order to facilitate diet adherence to the prescribed diet and preparation of healthy satiating meals, one main course per day (lunch or dinner) was provided to each subject on a weekly basis. These meals were served in large portions (four servings per meal) in order to let the participants eat until satiation was reached. They were low energy density $(<6.3 \mathrm{~kJ} / \mathrm{g}(<1.5 \mathrm{kcal} / \mathrm{g}))$, made with mostly low glycaemic index foods (glycaemic index factor $\leq 55^{(25)}$ ), and contained capsaicin (red chili pepper). One serving of each meal provided $<2092 \mathrm{~kJ}$ (<500 kcal), $>25 \%$ energy from proteins, $<25 \%$ energy from lipids (mainly PUFA and MUFA) and $>8 \mathrm{~g}$ of fibres (see e.g. satiating meal ${ }^{(26)}$ ). Participants were encouraged to consume this satiating diet until satiety for a 16-week period even if a resistance to weight loss was observed during the protocol. The control diet (Table 1) provided 10-15\%, 55-60 and 30\% energy as protein, carbohydrate and lipid, respectively. Food was self-selected 
Table 1. Description of the control and the satiating diets

\begin{tabular}{|c|c|c|}
\hline & Control diet & Satiating diet \\
\hline Based on & Canadian Food Guide for Healthy Eating & Scientific evidence \\
\hline $\begin{array}{l}\% \text { of energy from } \\
\text { macronutrients }\end{array}$ & $\begin{array}{l}10-15 \% \text { proteins } \\
30 \% \text { lipids } \\
55-60 \% \text { carbohydrates }\end{array}$ & $\begin{array}{l}20-25 \% \text { proteins } \\
30-35 \% \text { lipids } \\
45-50 \% \text { carbohydrates }\end{array}$ \\
\hline Main course provided? & No & Yes (one main course per day) \\
\hline $\begin{array}{l}\text { General guidelines for } \\
\text { participants }\end{array}$ & $\begin{array}{l}\text { Eat from four dietary groups: } \\
\text { - Grain products: } 5-12 \text { servings/d; } \\
\text { - Vegetables and fruit: } 5-10 \text { servings/d; } \\
\text { - Dairy products: } 2-4 \text { servings/d; } \\
\text { - Meat and alternatives: } 2-3 \text { servings/d } \\
\text { Other directives: } \\
\text { - Eat less fat; } \\
\text { - Choose enriched or whole grains } \\
\text { - } \text { products; } \\
\text { - Eut some colour in your plate; } \\
\text { - } \text { yogurt } \leq 2 \% \text { fat, cheese } \leq 20 \% \text { fat); } \\
\text { - Eat legumes; } \\
\text { - Drink enough water; } \\
\text { - Drink alcohol and caffeinated beverages } \\
\text { - } \text { with moderation; } \\
\text { Lower your salt consumption }\end{array}$ & $\begin{array}{l}\text { Each day, consume at least: } \\
\text { - } 4 \text { servings of whole fruits; } \\
\text { - } 4 \text { servings of whole vegetables; } \\
\text { - } 5 \text { servings of whole-grain products that are rich in fibre (at least } 4 \mathrm{~g} \text { of fibre } \\
\text { per portion); } \\
\text { - } 4 \text { equivalents of lean protein sources in each meal: meat, poultry, fish, eggs, } \\
\quad \text { milk and dairy products, nuts and seeds, tofu and soya (if not possible to include } \\
\text { - } 4 \text { equivalents of lean protein in a meal, add them in snacks); } \\
\text { Other directives: } \\
\text { - Have one legume meal per week; } \\
\text { - Consume fats moderately (mainly MUFA and PUFA); } \\
\text { - } \text { Avoid trans-fatty acids, hydrogenated fatty acids and SFA; }\end{array}$ \\
\hline
\end{tabular}

Table 2. Dietary guidelines and examples of portion size for the satiating diet

\begin{tabular}{|c|c|}
\hline Dietary guidelines & Examples of one serving size \\
\hline 4 servings of whole fruits/d & $\begin{array}{l}\text { - } 1 \text { apple; } \\
\text { - } 1 \text { orange; } \\
\text { - } 1 \text { medium-sized banana; and } \\
\text { - } 1 / 2 \text { cup of fruits (fresh, frozen, canned) }\end{array}$ \\
\hline $\begin{array}{l}4 \text { servings of whole } \\
\text { vegetables/d }\end{array}$ & $\begin{array}{l}\text { - } 1 \text { cup of salad; } \\
\text { - } 1 \text { cup of vegetable soup; } \\
\text { - } 1 \text { medium-sized carrot; and } \\
\text { - } 1 / 2 \text { cup of vegetables } \\
\text { (fresh, frozen, canned) }\end{array}$ \\
\hline $\begin{array}{l}5 \text { servings of whole-grain } \\
\text { products that are rich in } \\
\text { fibre (at least } 4 \mathrm{~g} \text { of fibre } \\
\text { per portion) } / \mathrm{d}\end{array}$ & $\begin{array}{l}\text { - } 1 \text { slice of whole-grain bread; } \\
\text { - } 1 / 2 \text { whole-grain bagel or pita bread; } \\
\text { - } 1 / 2 \text { cup of brown rice (cooked); } \\
\text { - } 1 / 2 \text { cup of whole wheat pasta (cooked); } \\
\text { - } 30 \mathrm{~g} \text { of ready-to-eat cereals (with } \geq 4 \mathrm{~g} \\
\text { fibre); } \\
\text { - } 3 / 4 \text { cup of oatmeal (cooked); and } \\
\text { - } 4-6 \text { whole-grain crackers }\end{array}$ \\
\hline $\begin{array}{l}4 \text { equivalents of lean protein } \\
\text { sources in each meal } \\
\text { (if not possible to include } 4 \\
\text { equivalents of lean protein } \\
\text { in a meal, add them to } \\
\text { snacks) }\end{array}$ & 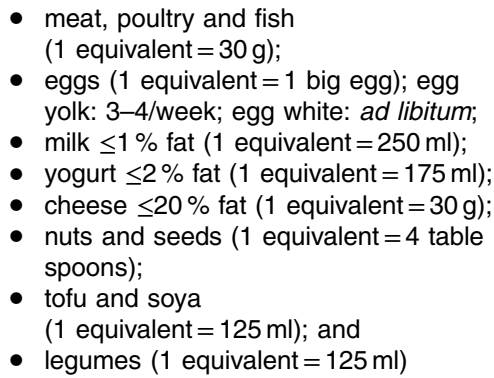 \\
\hline
\end{tabular}

with the help of nutritional guidelines based on the Canadian Food Guide $^{(16)}$ and under supervision of the nutritionist. Participants were not aware that the guidelines were coming from the
Canadian Food Guide. In both groups, individual follow-up visits (every 2 weeks) with a nutritionist were provided and permitted the assessment of compliance and dietary intakes. Of note, neither of the diets were restrained in carbohydrates (both diets were $>45 \%$ carbohydrates) and there were no acute changes in the diet composition throughout the study (i.e. participants followed the same diet for a 16-week period). Moreover, no exercise prescription was included in this intervention and participants were asked to maintain their same low physical activity level.

Post-study measurements (V3). Anthropometric measures and body composition, eating behaviour traits and satiety responsiveness were reassessed immediately after the 16-week intervention period.

\section{Statistical analyses}

The sample size was originally calculated based on the main outcome of this study (i.e. to induce a significant weight loss after 16 weeks on a highly satiating diet) and revealed that for an $\alpha \leq 0.05$ and a $1-\beta$ of $95 \%$, a total of only forty-seven participants would be needed in order to detect a $3.5 \mathrm{~kg}$ difference between the pre and post intervention with a SD of 1.5 . Based on our previous studies, a dropout rate of $30 \%$ was anticipated increasing the number of participants to sixty-eight participants. The sample size of sixty-nine participants, 35 in the intervention and 34 in the control group, offered about $94 \%$ power to detect an effect size of 0.25 in continuous outcomes (e.g. body weight) and an $\alpha \leq 0.05$ two-sided type I error rate.

Baseline characteristics were obtained for all participants. Statistical analysis of differences between the groups was performed using a two-factor mixed ANOVA for independent groups. A student $t$ test was used to compare baseline 
characteristics between completers and dropouts. A paired $t$ test was used to compare baseline and post-intervention values within the groups. A two-factor mixed ANOVA for independent groups was used to evaluate the effect of diet (control diet $v$. satiating diet), satiety phenotype (LSP $v$. HSP) and the diet $\times \mathrm{SP}$ interaction on changes in body weight, body composition, energy intake and SQ following the dietary interventions. These analyses were adjusted for baseline values for each variable. Data were expressed as means and standard deviations and statistical significance was set to a $P<0 \cdot 05$. All statistical analyses were performed using the JMP software version 12.0 (SAS Institute, Cary, NC, USA).

\section{Results}

\section{Baseline characteristics}

Baseline characteristics of all participants are presented in Table 3. There were no significant differences in anthropometric measures. As expected, the SQ for each appetite sensation and the mean SQ were significantly different between the satiety phenotype subgroups (LSP $v$. HSP). With the exception of the disinhibition score, which was significantly higher in the satiating diet group $(P=0.004)$, there were no differences between groups for eating behaviour traits.

\section{Adherence}

Of the sixty-nine men who were randomised into the diet groups, fifty-one completed the study (control diet: $n$ 19; satiating diet: $n$ 32). Dropout rates were higher in the control diet (44.1\%) compared with the satiating diet (8.6\%). Six LSP and nine HSP individuals dropped out of the control diet, whereas two LSP and one HSP individual dropped out of the satiating diet. In the control group, the reasons for dropping out were: lack of availability or time (5/15), lack of motivation (4/15), dissatisfaction with the diet (1/15) or the nutritional follow-up (1/15), wanting to start the Atkin's diet (1/15), wanting to enroll in a physical activity programme (1/15), job loss and emotional shock (1/15), and no longer responding $(1 / 15)$. In the satiating group, the reasons for dropping out were: dissatisfaction with the prepared meals $(1 / 3)$, lack of time (1/3) and no longer responding (1/3).

Table 4 compares the baseline characteristics between the completers and dropouts, irrespective of the diet group. Percent fat mass, which was significantly higher in the dropouts than the completers $(P=0 \cdot 021)$, was the only difference. Further comparisons of baseline characteristics between completers ( $n$ 19) and dropouts ( $n$ 15) inside the control group were done. Percent fat mass was higher in the dropouts than the completers ( $P=0.006$, results not shown) and there was a tendency for the dropout participants to show higher rigid control than the completers $(P=0 \cdot 058$, results not shown).

\section{Comparison between baseline and post-intervention values}

Table 5 compares baseline and post-intervention values within each subgroup and shows an effect of diet, satiety phenotype and their interaction following the intervention.

\section{Changes in anthropometric variables}

Significant decreases in body weight, BMI and waist circumference were observed in all diet subgroups. Fat mass and lean body mass significantly decreased in the satiating diet (both LSP and HSP subgroups) and in the control group (HSP

Table 3. Baseline characteristics of the participants

(Mean values and standard deviations)

\begin{tabular}{|c|c|c|c|c|c|c|c|c|c|c|c|}
\hline & \multicolumn{4}{|c|}{ Control diet ( $n$ 34) } & \multicolumn{4}{|c|}{ Satiating diet (n 35) } & & & \\
\hline & \multicolumn{2}{|c|}{$\operatorname{LSP}(n 15)$} & \multicolumn{2}{|c|}{$\operatorname{HSP}(n=19)$} & \multicolumn{2}{|c|}{$\mathrm{LSP}(n 17)$} & \multicolumn{2}{|c|}{$\mathrm{HSP}(n 18)$} & \multicolumn{3}{|c|}{$P$} \\
\hline & Mean & SD & Mean & $\mathrm{SD}$ & Mean & SD & Mean & SD & Diet & $\mathrm{SP}$ & Diet $\times$ SP \\
\hline Age (years) & $41 \cdot 0$ & $6 \cdot 3$ & 41.9 & 5.5 & $40 \cdot 4$ & $6 \cdot 2$ & 42.55 & $5 \cdot 0$ & 0.999 & 0.270 & 0.648 \\
\hline \multicolumn{12}{|l|}{ Anthropometric measurements } \\
\hline Body weight (kg) & $101 \cdot 2$ & $11 \cdot 0$ & $102 \cdot 4$ & $14 \cdot 5$ & $105 \cdot 2$ & 8.8 & $96 \cdot 5$ & $10 \cdot 0$ & 0.739 & 0.175 & 0.078 \\
\hline $\operatorname{BMI}\left(\mathrm{kg} / \mathrm{m}^{2}\right)$ & 34.1 & 3.5 & 33.9 & $2 \cdot 8$ & $33 \cdot 6$ & 3.0 & 32.9 & 2.9 & 0.326 & 0.553 & 0.757 \\
\hline Waist circumference $(\mathrm{cm})$ & 111.7 & 8.6 & 114.4 & $6 \cdot 7$ & 111.5 & $6 \cdot 6$ & $109 \cdot 1$ & $8 \cdot 5$ & 0.142 & 0.923 & 0.164 \\
\hline Fat mass (kg) & $34 \cdot 3$ & $6 \cdot 7$ & $36 \cdot 0$ & 8.7 & 34.9 & 6.5 & $32 \cdot 5$ & $6 \cdot 1$ & 0.411 & 0.864 & 0.238 \\
\hline Lean body mass (kg) & $67 \cdot 0$ & $7 \cdot 4$ & $66 \cdot 4$ & $9 \cdot 2$ & $70 \cdot 3$ & 4.9 & $64 \cdot 0$ & $7 \cdot 5$ & 0.785 & 0.059 & 0.116 \\
\hline$\%$ Fat mass & $33 \cdot 7$ & 4.5 & $35 \cdot 0$ & $5 \cdot 2$ & $33 \cdot 0$ & $4 \cdot 1$ & 33.7 & $4 \cdot 8$ & 0.365 & 0.398 & 0.804 \\
\hline \multicolumn{12}{|l|}{ Satiety responsiveness } \\
\hline $\mathrm{SQ}$ desire to eat $(\mathrm{mm} / 418 \mathrm{~kJ}(100 \mathrm{kcal}))$ & $7 \cdot 4$ & $5 \cdot 1$ & $10 \cdot 3$ & $4 \cdot 0$ & $6 \cdot 6$ & 4.9 & $11 \cdot 3$ & $5 \cdot 5$ & 0.905 & 0.002 & 0.450 \\
\hline $\mathrm{SQ}$ hunger $(\mathrm{mm} / 418 \mathrm{~kJ}(100 \mathrm{kcal}))$ & $7 \cdot 3$ & 4.9 & $10 \cdot 1$ & $4 \cdot 3$ & $6 \cdot 7$ & $6 \cdot 4$ & $11 \cdot 4$ & $4 \cdot 8$ & 0.763 & 0.003 & 0.436 \\
\hline $\mathrm{SQ}$ fullness $(\mathrm{mm} / 418 \mathrm{~kJ}(100 \mathrm{kcal}))$ & $7 \cdot 8$ & $5 \cdot 5$ & 11.4 & $4 \cdot 2$ & $6 \cdot 0$ & 6.5 & $14 \cdot 2$ & $3 \cdot 7$ & 0.673 & $<0.0001$ & 0.062 \\
\hline SQ PFC (mm/418kJ (100 kcal)) & $6 \cdot 3$ & $5 \cdot 2$ & $8 \cdot 6$ & $4 \cdot 3$ & $4 \cdot 1$ & $6 \cdot 0$ & $10 \cdot 4$ & $4 \cdot 7$ & 0.869 & 0.001 & 0.107 \\
\hline $\mathrm{SQ}$ mean $(\mathrm{mm} / 418 \mathrm{~kJ}(100 \mathrm{kcal}))$ & $7 \cdot 2$ & $4 \cdot 9$ & $10 \cdot 1$ & 3.6 & $5 \cdot 8$ & $4 \cdot 8$ & 11.9 & $4 \cdot 1$ & 0.844 & $<0.0001$ & 0.145 \\
\hline \multicolumn{12}{|l|}{ Eating behaviour traits } \\
\hline Cognitive dietary restraint $(0-21)$ & $4 \cdot 9$ & $2 \cdot 3$ & $5 \cdot 3$ & 2.4 & $5 \cdot 6$ & $2 \cdot 6$ & $5 \cdot 1$ & 1.9 & 0.705 & 0.873 & 0.485 \\
\hline Flexible control (0-7) & $1 \cdot 3$ & $1 \cdot 1$ & 1.6 & 1.0 & $1 \cdot 3$ & 1.6 & 1.6 & $1 \cdot 1$ & 0.890 & 0.331 & 0.986 \\
\hline Rigid control (0-7) & 1.5 & $1 \cdot 1$ & $1 \cdot 3$ & 1.4 & 1.9 & 1.2 & 1.5 & 0.9 & 0.199 & 0.286 & 0.724 \\
\hline Disinhibition (0-16) & $7 \cdot 7$ & $3 \cdot 0$ & $7 \cdot 8$ & 3.2 & $10 \cdot 0$ & $2 \cdot 7$ & $10 \cdot 0$ & $3 \cdot 0$ & 0.004 & 0.966 & 0.966 \\
\hline Susceptibility to hunger (0-14) & $6 \cdot 9$ & 2.9 & $6 \cdot 2$ & $3 \cdot 8$ & 8.4 & 3.4 & $7 \cdot 1$ & 3.9 & 0.191 & 0.272 & 0.692 \\
\hline
\end{tabular}

LSP, low satiety phenotype; HSP, high satiety phenotype; SP, satiety phenotype; SQ, satiety quotient; PFC, prospective food consumption. 
Table 4. Comparison of the baseline characteristics of the completers and dropouts (both diet groups) (Mean values and standard deviations)

\begin{tabular}{|c|c|c|c|c|c|}
\hline & \multicolumn{2}{|c|}{ Completers ( $n$ 51) } & \multicolumn{2}{|c|}{ Dropouts (n 18) } & \multirow[b]{2}{*}{$P$} \\
\hline & Mean & $\mathrm{SD}$ & Mean & $\mathrm{SD}$ & \\
\hline Age (years) & 41.9 & $5 \cdot 4$ & 40.5 & $6 \cdot 2$ & 0.355 \\
\hline \multicolumn{6}{|l|}{ Anthropometric measurements } \\
\hline Body weight $(\mathrm{kg})$ & $101 \cdot 0$ & $11 \cdot 3$ & $102 \cdot 3$ & $12 \cdot 4$ & 0.690 \\
\hline BMI $\left(\mathrm{kg} / \mathrm{m}^{2}\right)$ & 33.5 & $3 \cdot 1$ & $34 \cdot 0$ & 2.8 & 0.540 \\
\hline Waist circumference (cm) & 111.0 & $8 \cdot 2$ & 113.7 & $6 \cdot 0$ & 0.211 \\
\hline Fat mass $(\mathrm{kg})$ & 33.6 & $6 \cdot 6$ & $37 \cdot 1$ & 8.0 & 0.076 \\
\hline Lean body mass $(\mathrm{kg})$ & $67 \cdot 4$ & $7 \cdot 5$ & $65 \cdot 2$ & $8 \cdot 1$ & 0.306 \\
\hline$\%$ Fat mass & $33 \cdot 1$ & $4 \cdot 2$ & $36 \cdot 1$ & $5 \cdot 2$ & 0.021 \\
\hline \multicolumn{6}{|l|}{ Satiety responsiveness } \\
\hline $\mathrm{SQ}$ desire to eat $(\mathrm{mm} / 418 \mathrm{~kJ}(100 \mathrm{kcal}))$ & 8.8 & $5 \cdot 6$ & 9.7 & 3.9 & 0.545 \\
\hline $\mathrm{SQ}$ hunger (mm/418 kJ (100 kcal)) & 8.8 & $5 \cdot 9$ & $9 \cdot 4$ & 3.9 & 0.699 \\
\hline SQ fullness $(\mathrm{mm} / 418 \mathrm{~kJ}(100 \mathrm{kcal}))$ & $10 \cdot 6$ & $5 \cdot 8$ & $8 \cdot 3$ & $5 \cdot 8$ & 0.157 \\
\hline SQ PFC (mm/418 kJ (100 kcal)) & $7 \cdot 7$ & $6 \cdot 0$ & $6 \cdot 9$ & $4 \cdot 2$ & 0.617 \\
\hline $\mathrm{SQ}$ mean $(\mathrm{mm} / 418 \mathrm{~kJ}(100 \mathrm{kcal}))$ & $9 \cdot 0$ & $5 \cdot 3$ & 8.6 & 3.4 & 0.766 \\
\hline \multicolumn{6}{|l|}{ Eating behaviour traits } \\
\hline Cognitive dietary restraint $(0-21)$ & $5 \cdot 3$ & $2 \cdot 1$ & $5 \cdot 0$ & 2.7 & 0.689 \\
\hline Flexible control (0-7) & 1.6 & $1 \cdot 2$ & $1 \cdot 2$ & 1.0 & 0.269 \\
\hline Rigid control $(0-7)$ & 1.4 & 1.0 & 1.8 & 1.4 & 0.284 \\
\hline Disinhibition (0-16) & $9 \cdot 2$ & 2.9 & $7 \cdot 9$ & 3.6 & 0.141 \\
\hline Susceptibility to hunger $(0-14)$ & 7.5 & 3.3 & $6 \cdot 0$ & $4 \cdot 0$ & $0 \cdot 151$ \\
\hline
\end{tabular}

$\mathrm{SQ}$, satiety quotient; PFC, prospective food consumption.

Table 5. Changes in anthropometric measures, satiety responsiveness and eating behaviour traits in the completers (Mean values and standard deviations)

\begin{tabular}{|c|c|c|c|c|c|c|c|c|c|c|c|}
\hline \multirow[b]{3}{*}{ Post-baseline values } & \multicolumn{4}{|c|}{ Control diet (n 19) } & \multicolumn{4}{|c|}{ Satiating diet ( $n$ 32) } & & & \\
\hline & \multicolumn{2}{|c|}{$\operatorname{LSP}(n 9)$} & \multicolumn{2}{|c|}{$\operatorname{HSP}(n 10)$} & \multicolumn{2}{|c|}{$\operatorname{LSP}(n 15)$} & \multicolumn{2}{|c|}{$\mathrm{HSP}(n 17)$} & \multicolumn{3}{|c|}{ Adjusted $P$} \\
\hline & Mean & SD & Mean & SD & Mean & $\mathrm{SD}$ & Mean & SD & Diet & $\mathrm{SP}$ & Diet $\times$ SP \\
\hline \multicolumn{12}{|l|}{ Delta anthropometric measurements } \\
\hline Body weight $(\mathrm{kg})$ & $-3 \cdot 2^{*}$ & 2.9 & $-5 \cdot 6^{\star \star}$ & $4 \cdot 0$ & $-4 \cdot 5^{\star \star \star}$ & $3 \cdot 1$ & $-6 \cdot 4^{\star \star \star}$ & $5 \cdot 8$ & 0.32 & 0.048 & 0.53 \\
\hline BMI $\left(\mathrm{kg} / \mathrm{m}^{2}\right)$ & $-1 \cdot 0^{\star \star}$ & 0.9 & $-1 \cdot 8^{\star \star}$ & $1 \cdot 3$ & $-1 \cdot 4^{\star \star \star}$ & 1.0 & $-2 \cdot 1^{\star \star \star}$ & $1 \cdot 8$ & 0.34 & 0.073 & 0.999 \\
\hline Waist circumference (cm) & $-4 \cdot 5^{\star \star \star}$ & 2.6 & $-5 \cdot 4^{\star \star \star}$ & $3 \cdot 3$ & $-4 \cdot 9^{\star \star \star}$ & 3.8 & $-6 \cdot 5^{\star \star \star}$ & 4.9 & 0.45 & 0.33 & 0.58 \\
\hline Fat mass $(\mathrm{kg})$ & -1.9 & $3 \cdot 1$ & $-2 \cdot 9^{\star}$ & $3 \cdot 3$ & $-3 \cdot 5^{\star \star \star}$ & $2 \cdot 8$ & $-4 \cdot 8^{\star \star \star}$ & 3.9 & 0.085 & 0.25 & 0.94 \\
\hline Lean body mass $(\mathrm{kg})$ & $-1.3 \dagger$ & $1 \cdot 7$ & $-2 \cdot 7^{\star}$ & 2.7 & $-1 \cdot 0^{\star}$ & 1.5 & $-1 \cdot 6^{\star}$ & 2.6 & 0.49 & 0.033 & 0.38 \\
\hline \multicolumn{12}{|l|}{ Delta satiety responsiveness } \\
\hline $\mathrm{SQ}$ desire to eat $(\mathrm{mm} / 418 \mathrm{~kJ}(100 \mathrm{kcal}))$ & 1.5 & $5 \cdot 5$ & $1 \cdot 0$ & 4.9 & $5 \cdot 6^{\star \star \star}$ & $4 \cdot 0$ & 1.9 & 4.9 & 0.055 & 0.73 & 0.76 \\
\hline SQ hunger (mm/418 kJ (100 kcal)) & $2 \cdot 0$ & $6 \cdot 6$ & -0.3 & $3 \cdot 8$ & $5 \cdot 4^{\star \star \star}$ & $4 \cdot 3$ & $2 \cdot 4^{\star}$ & 4.4 & 0.011 & 0.71 & 0.78 \\
\hline SQ fullness (mm/418 kJ (100 kcal)) & -0.4 & $5 \cdot 3$ & $-0 \cdot 1$ & 3.6 & $3 \cdot 6^{\star \star}$ & $4 \cdot 1$ & 0.3 & $4 \cdot 1$ & 0.034 & 0.61 & 0.28 \\
\hline SQ PFC (mm/418 kJ (100 kcal)) & -0.6 & 4.5 & $-2.0 \dagger$ & 2.8 & $4 \cdot 5^{\star \star}$ & $5 \cdot 7$ & $1 \cdot 3$ & $4 \cdot 3$ & 0.002 & 0.80 & 0.74 \\
\hline $\mathrm{SQ}$ mean $(\mathrm{mm} / 418 \mathrm{~kJ}(100 \mathrm{kcal}))$ & 0.6 & $4 \cdot 7$ & -0.4 & 3.0 & $4 \cdot 8^{\star \star \star}$ & $3 \cdot 1$ & 1.5 & 3.8 & 0.003 & 0.80 & 0.67 \\
\hline \multicolumn{12}{|l|}{ Delta eating behaviour traits } \\
\hline Cognitive dietary restraint & $6 \cdot 2 \dagger$ & $6 \cdot 1$ & $5 \cdot 6^{*}$ & 3.5 & $3 \cdot 3^{\star \star}$ & 2.9 & $7 \cdot 2^{\star \star \star}$ & $5 \cdot 5$ & 0.96 & 0.36 & 0.34 \\
\hline Flexible control & $2.3+$ & $2 \cdot 6$ & 1.4 & 1.8 & $0.9+$ & 1.4 & $2 \cdot 3^{\star}$ & 2.7 & 0.83 & 0.49 & 0.28 \\
\hline Rigid control & $2 \cdot 2^{*}$ & $1 \cdot 7$ & $2.5 \dagger$ & $2 \cdot 8$ & 0.7 & $1 \cdot 3$ & $2 \cdot 2^{\star \star \star}$ & 1.5 & 0.65 & 0.25 & 0.54 \\
\hline Disinhibition & $-3 \cdot 2^{*}$ & 2.6 & $-2 \cdot 8$ & 3.8 & $-2 \cdot 8^{\star}$ & $3 \cdot 7$ & $-3 \cdot 2^{\star \star \star}$ & $2 \cdot 1$ & 0.77 & 0.86 & 0.50 \\
\hline Susceptibility to hunger & $-4 \cdot 1^{*}$ & 3.5 & $-3 \cdot 3 \dagger$ & 3.9 & $-2 \cdot 7 \dagger$ & $4 \cdot 1$ & $-4 \cdot 6^{\star \star}$ & 3.9 & 0.62 & 0.87 & 0.074 \\
\hline
\end{tabular}

LSP, low satiety phenotype; HSP, high satiety phenotype; SP, satiety phenotype; SQ, satiety quotient; PFC, prospective food consumption.

Post-intervention values were significantly different from baseline values: ${ }^{\star} P<0.05,{ }^{\star \star} P<0.01,{ }^{\star \star \star}{ }^{*} P<0.001, \dagger P$ between 0.05 and 0.095 .

subgroups only). Lean body mass also decreased in the LSPcontrol subgroup $(P=0 \cdot 05)$. Percent fat mass was significantly reduced following the satiating diet only (LSP and HSP subgroups). After adjustment for baseline values, the analyses revealed a significant effect of diet on the changes in \% fat mass, with greater decreases observed in both LSP and HSP individuals in the satiating compared with the control group ( $P=0.034$; see Fig. 2 ). There was an effect of satiety phenotype on the changes in body weight and lean body mass, irrespective of diet allocation. The LSP individuals have lost significantly less weight $(P=0.048)$ and lean body mass $(P=0.033)$ than their HSP counterparts.

\section{Changes in satiety responsiveness}

Significant increases from baseline in satiety responsiveness (all SQ variables) for the LSP in the satiating diet were observed 


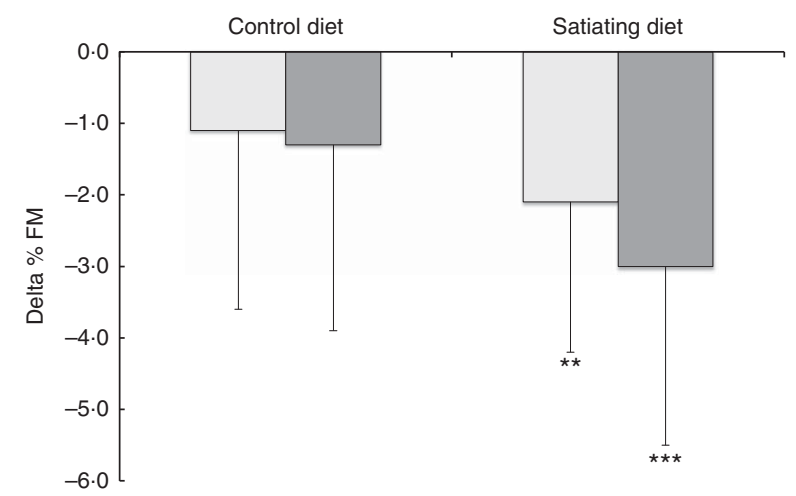

Fig. 2. Changes in percent fat mass (\% FM) in the satiety phenotype subgroups following the weight loss programme. Values are means, with their standard deviations represented by vertical bars. $\square$, low satiety phenotype (LSP); $\square$, high satiety phenotype (HSP). Percent fat mass significantly reduced following the satiating diet only $\left({ }^{\star *} P<0.01,{ }^{* \star *} P<0.001\right)$. There was a significant effect of diet on the changes in \% FM, with greater decreases observed in both LSP and HSP individuals in the satiating compared with the control group $(P=0.034)$. The effect of the satiety phenotype $(P=0.42)$ and the interaction between diet and satiety phenotype $(P=0.54)$ were not statistically significant.

(all $P<0 \cdot 01$ ). SQ hunger also significantly increased for the HSP individuals in the satiating diet $(P<0.05)$. SQ PFC tended to decrease in the HSP-control subgroup $(P=0.0504)$. There were no other significant changes in satiety responsiveness in the control group. After adjustment for baseline variables, there was a significant effect of diet for the changes in SQ hunger, fullness, PFC and mean SQ (all $P<0.05$ ), with greater increases in SQ for the satiating diet.

\section{Changes in eating behaviour traits}

The HSP individuals in the satiating diet showed significant increases in cognitive dietary restraint, flexible control and rigid control scores, and significant decreases in disinhibition and susceptibility to hunger scores. The HSP individuals in the control diet showed significant increases in cognitive dietary restraint, as well as tendencies for an increase in rigid control $(P=0.0812)$ and a decrease in susceptibility to hunger $(P=0.0925)$. The LSP individuals in the satiating diet showed a significant increase in cognitive dietary restraint and a decrease in disinhibition, as well as tendencies for an increase in flexible control $(P=0.0864)$ and decrease in susceptibility to hunger $(P=0.0691)$. The LSP individuals in the control diet showed tendencies for increases in cognitive dietary restraint $(P=0.0565)$ and flexible control $(P=0.0564)$, as well as a significant increase in rigid control and significant decreases in disinhibition and susceptibility to hunger. There was no significant effect of diet, SP or their interaction on the changes in eating behaviour traits.

\section{Discussion}

A major concern regarding conventional energy restriction approaches for the treatment of obesity is the lack of consideration for inter-individual differences in appetite control. Consequently, adherence to restrictive diets and weight management may become difficult. In this regard, the main objective of this study was to evaluate the impact of a non-restrictive (ad libitum), highly satiating diet on body weight and composition, satiety responsiveness, eating behaviour traits and adherence in obese men characterised by low or high satiety responsiveness.

Body weight and BMI were significantly reduced in the control and satiating diets. Not surprisingly, greater reductions in body weight were observed in HSP men $(-5.4$ to $-6.6 \%$ of initial body weight) compared with LSP men ( -3.3 to $-4.3 \%$ of initial body weight), irrespective of treatment allocation. As a weight reduction of $5-10 \%$ of initial body weight has been shown to have important health benefits ${ }^{(27)}$, this may lead to positive overall health outcomes. Furthermore, the significant decrease in waist circumference observed in all subgroups also suggests that some loss of abdominal adipose tissue was obtained $^{(28)}$, a reduction also predictive of improvements in the metabolic profile and cardiovascular health ${ }^{(29)}$.

The lower body weight loss observed in the LSP could be explained by their different behavioural and psychological characteristics. Accordingly, it has been shown that the LSP is associated with a higher disinhibition trait ${ }^{(2,20)}$, higher susceptibility for hunger and anxiety traits $^{(6)}$ compared with the normal/HSP, which could increase their risk of overeating. Moreover, it has also been shown that these individuals present greater wanting for high-fat foods and express lower control over food cravings ${ }^{(20)}$. Together, these observations suggest that the LSP could present more difficulties in following a weight loss diet intervention over time, resulting in lower body weight loss compared with the HSP. However, even though the LSP lost less body weight than the HSP, their body composition improved to the same extent as the HSP under the high satiating diet.

Interestingly, although absolute fat mass was not significantly decreased in the LSP individuals on the control diet, they displayed a significant reduction in their lean body mass. Moreover, there was a tendency $(P=0.085)$ for significant loss in fat mass on the satiating diet compared with the control diet. As a result, significant decreases in \% fat mass were observed in LSP $(-2 \cdot 1 \%)$ and HSP $(-3.0 \%)$ individuals on the satiating diet only, who lost approximately two times more \% fat mass than their LSP $(-1 \cdot 1 \%)$ and HSP $(-1 \cdot 3 \%)$ counterparts in the control group. This may be explained by the greater protein content of the satiating (20-25\%) compared with the control diet (10-15\%). In fact, evidence suggests that high intakes of total dietary protein $(1 \cdot 2-1.5 \mathrm{~g} / \mathrm{kg}$ per d) may help preserve lean mass and improve body composition during weight loss in young, middle-aged, and older adults when compared with normal protein intakes $(0.8 \mathrm{~g} / \mathrm{kg} \text { per } \mathrm{d})^{(30-32)}$.

Both diets promoted a significant spontaneous energy deficit; however, only the satiating diet had a beneficial influence on satiety responsiveness. In the control diet, SQ did not change or tended to decrease (i.e. satiety responsiveness remained similar), irrespective of the satiety phenotype. This agrees with a previous study reporting that, after a weight loss programme, the decrease in body fat mass was associated with an increase in the desire to eat and a decrease in the sensation of fullness ${ }^{(33)}$. In the satiating diet, however, significant increases in satiety responsiveness were observed in both LSP and HSP 
individuals, despite significant decreases in body weight (more in HSP) and \% fat mass. Of note, significant increases in all SQ (SQ desire to eat, SQ hunger, SQ fullness, SQ PFC and SQ mean) were found in LSP individuals ( +3.6 (SD 4.1) to +5.6 (sD 4.0$) \mathrm{mm} / 418 \mathrm{~kJ}(100 \mathrm{kcal})$; all $P<0 \cdot 01)$, whereas SQ hunger also increased significantly in HSP individuals $(+2 \cdot 4$ (SD 4.4$) \mathrm{mm} /$ $418 \mathrm{~kJ}$ (100 kcal); $P<0 \cdot 05)$. This suggests that, even under conditions of body weight and fat mass loss, not only could satiety responsiveness be globally improved in individuals lacking satiety efficiency, but it may also be further improved in individuals who already have a normal/high satiety efficiency.

Such differences in satiety responsiveness between the satiating and control diets (as well as differences in adherence rates) may be explained by the combination of different satietyenhancing foods in the experimental diet. First, the low energy density (energy per unit weight) of the highly satiating diet could explain the effect on satiety responsiveness and body weight. Accordingly, it has been shown that because individuals tend to eat a consistent weight of food, reducing the energy density will spontaneously reduce the energy intake of the meal $^{(9)}$. With respect to satiety, low energy dense foods have been successfully used to reduce energy intake at a subsequent meal ${ }^{(34-36)}$. Furthermore, strong and consistent evidence in the adult population indicates that dietary patterns relatively low in energy density improve weight loss and weight maintenance ${ }^{(37)}$. Variations in energy density can be easily achieved by manipulating the proportion of fat, fruits and vegetables or water in a meal $^{(38)}$. The mechanisms underlying the response to variations in energy density are not well understood but could involve sensory factors related to food volume which influence gastric distension and gastric emptying rate ${ }^{(9)}$, or cognitive factors, such as beliefs about the satiating capacity of different foods ${ }^{(39)}$.

Second, the higher protein content of the satiating diet could also be involved in this effect. Accordingly, evidence suggests that high-protein diets ( $>20 \%$ of energy from protein) are more satiating and have a higher thermogenic effect than normal protein diets ( $<20 \%$ of energy from protein) over the short and long term $^{(10,40,41)}$, and could be an effective strategy to prevent weight regain $^{(42)}$. The effect of protein on satiety is nutrient-specific (different proteins cause different effects) ${ }^{(43)}$ and seems to be due to increased diet-induced thermogenesis, specifically with animal protein, and to their influence on meal-induced anorexic gut peptides (glucagon-like peptide- 1 and peptide YY release) ${ }^{(44,45)}$.

Next, the glycaemic index and fibre content of the satiating diet could also explain the results. Short-term studies have shown that the ingestion of low glycaemic index foods can acutely increase satiety and reduce subsequent energy intake $^{(46,47)}$. The consumption of a low glycaemic index diet could also help long-term weight maintenance after energetic restriction $^{(42)}$. Although, more recently, the role of glycemic index per se in appetite control and weight loss has been questioned $^{(48)}$, it is believed that many unprocessed, low glycaemic index foods are high in fibre and proteins and have a low energy density ${ }^{(25)}$; factors which are known to contribute to appetite and body weight control. Epidemiological and longitudinal studies consistently show that diets higher in dietary fibre or an increase in dietary fibre is associated with lower body weights ${ }^{(12)}$ and small but significant reduction in weight gain over time ${ }^{(49)}$. In line with this, short-term intervention trials have shown that consumption of fibre results in modest improvements of satiety and body weight ${ }^{(50)}$. These effects can be explained by different mechanisms such as a reduction in nutrient absorption by the intestine, a decrease in energy density of foods ${ }^{(51)}$, an increase in mastication allowing more time for satiety signals to reach the brain ${ }^{(51)}$ as well as an increase in stomach distention by water absorption which in turn triggers afferent vagal signals of fullness ${ }^{(52)}$. Other functional nutrients that were added to the satiating diet and that may influence satiation and satiety and/or create a spontaneous decrease in energy intake include long-chain $n$-3 fatty acids ${ }^{(53)}, \mathrm{Ca}^{(14)}$ as well as capsaicinoids ${ }^{(15)}$. Thus, the many food properties and food composition of the highly satiating diet could have significantly influenced satiation and satiety, energy intake and body weight.

Finally, recent evidence suggests that the pre-ingestive appraisal of a food's satiating power, based on factors like its sensory profile or appearance, can alter the actual satiety responses to that specific food ${ }^{(54)}$. One of our previous studies have shown that satiety responses and appreciation towards a meal can be significantly modulated by a 'satiating context effect'. In this study, false suggestive information and cues (either verbal and visual) given to the participants about the 'highly satiating power' of that meal induced higher satiety responses and appreciation after the meal compared with no suggestive information and cues of the same meal ${ }^{(39)}$. Assuming that the two diets differed in their sensory profile and appearance (in part due to the presence of prepared meals in the satiating diet group), it is not excluded that satiety expectations could also have influenced satiation and satiety, as well as energy intake throughout the present study. However, we believe that such an effect in this context was minimised because participants were never informed about the satiating potential of the diets. Moreover, as mentioned by Chambers et al. ${ }^{(54)}$, satiety expectations have mostly been studied in isolation, and no studies have examined whether these effects on satiety persist with repeated consumption. Studies are thus needed to confirm if satiety expectations can play a role during long-term weight loss protocols.

Interestingly, in the present study, there were no baseline differences in any of the TFEQ scores between LSP and HSP individuals. This observation is concordant with previous studies that showed no relationship between the LSP and TFEQ eating behaviour traits in obese men ${ }^{(5,6)}$. In women, low satiety responsiveness was associated with high disinhibition ${ }^{(20)}$, which reflects the tendency for opportunistic eating ${ }^{(55)}$ and has been associated with an increase in spontaneous energy intake ${ }^{(56)}$ and weight gain ${ }^{(57)}$. It has been hypothesised that these sex discrepancies could be explained by the use of exclusion criteria regarding eating behaviours (such as high restraint eating scores) and the multifactorial control over appetite and eating behaviours ${ }^{(6)}$.

Despite higher body weight loss in the HSP and higher \% fat mass loss for the high satiating diet, our results showed no effect of the diet or the satiety phenotype for any of the measured behavioural variables. Globally, LSP and HSP individuals in both diets showed similar mean increases in cognitive dietary restraint, flexible control and rigid control, as well as mean decreases in disinhibition and susceptibility to hunger. 
Furthermore, despite similar fat mass and \% fat mass decreases within each diet group, the changes in eating behaviour traits (desirable or not) were comparable between LSP and HSP individuals. This result could be explained by the non-restrictive (ad libitum) nature of both diets. Therefore, the absence of planned, conscious energy restriction may counteract, at least partially, the undesirable impact of weight loss on eating behaviour traits in LSP individuals.

The difference in adherence rates between the satiating (91.4\%) and control (55.9\%) diets was also an important finding in the present study. Evidence suggests that the overall adherence rate in weight lost interventions is about $60.5 \%{ }^{(58)}$. The higher adherence rate that was observed in the experimental diet could be explained by factors related to some elements of the study design. For example, balanced/conventional and low-fat diets, because of their lower protein content, may be associated with cravings ${ }^{(59)}$. The experimental diet may have counteracted this issue by providing sufficient protein intake to maintain an acceptable level of satiety throughout the day. Another explanation could be the offering of ready-to-eat meals (one per day) that were palatable and time-convenient. The main reasons given by the participants at the time of dropping out were a lack of motivation, availability or time (60 and $33.3 \%$ of the dropouts in the control and the satiating diet, respectively) and dissatisfaction with the diet or nutritional follow-up ( 13.3 and $33.3 \%$ in the control and satiating diet, respectively). Even if not clearly stated by the participants who dropped out, the absence or presence of prepared meals could have partly influenced their level of motivation or satisfaction toward both diets. However, the nutritional follow-up was the same for both groups, suggesting that characteristics of the diets per se may have been major contributing factors for the differences in adherence rates. Below than expected weight loss may also have contributed to the lack of motivation and lack of adherence to the diet and could explain, at least partially, why more participants dropped out in the control group. Moreover, one can argue that differences in baseline eating behavioural traits of the participants could have played a role in compliance toward both diets. Our analyses showed significantly higher disinhibition scores for the individuals in the satiating diet group, irrespective of their satiety phenotype. This observation is surprising because it has been demonstrated that disinhibition is predictive of poorer success at weight loss ${ }^{(55)}$, and therefore one would expect more dropout or poorer outcomes in the satiating diet group. Comparisons of completers and dropouts (from both groups) showed no difference in their satiety responsiveness or eating behaviour traits, but further comparisons of completers and dropouts from the control group only demonstrated a tendency for the dropout participants to show higher rigid control than the completers $(P=0 \cdot 058$, results not shown). Like disinhibition, rigid dietary control strategies have been inversely related to dieting success ${ }^{(60)}$, and this result could suggest that this control diet was not suitable for high restrainers. Taken together, these observations demonstrate that the satiating diet succeeded to promote adherence in LSP and HSP, as well as in individuals demonstrating higher disinhibition, beyond what would be expected with a more traditional diet based on general healthy eating guidelines.
This study is not without some limitations. First, subjects were middle-aged men and the results could differ in other populations. Second, due to the high dropout rate observed in the control diet group, the final sample was smaller than what was expected and results should be interpreted as trends. It should also be kept in mind that participants in the control diet group, contrary to those in the satiating diet group, were not provided with the main course of the lunch or dinner on a weekly basis. In the informed consent, participants were told that only one of the two diet groups would receive these prepared meals. This information could have influenced the motivation or satisfaction toward the diet. However, the close individual supervision that was offered throughout the study was intended to minimise such dropouts. As discussed above, we did not collect data regarding the satiety expectations towards both diets, which could have given valuable additional information.

Finally, even though the present study focuses on interindividual differences in appetite responses and how to support individuals with LSP and HSP, it did not allow the quantification of true individual response differences. To quantify true individual response differences (i.e. not explained by random within-subject variation and the regression to the mean), Atkinson \& Batterham ${ }^{(61)}$ suggest to compare the standard deviations of changes between intervention and comparator (no intervention) arms. When these standard deviations are similar, true individual response differences are clinically unimportant. In the present study, standard deviation comparisons were not possible because of the absence of a nonintervention comparator arm and relatively small samples. Nevertheless, as highlighted by Atkinson \& Batterham, very few researchers have compared these standard deviations before drawing conclusions and extrapolating their results. Even though appetite sensation measurements have shown good short-term reproducibility ${ }^{(19)}$, we cannot exclude the possibility that differences in response found between the groups are the result of random within-subject variation, especially when there is considerable time (3-6 months) between baseline and followup measurements ${ }^{(62,63)}$. Future studies should use appropriate designs and analysis approaches for quantifying this true interindividual variations in satiety responses.

\section{Conclusion}

Despite higher overall body weight loss in the HSP compared with LSP groups, the ad libitum highly satiating diet resulted in twice the decrease in \% fat mass in both LSP and HSP obese men compared with a control healthy diet. This was combined with an improved satiety responsiveness, irrespective of the satiety phenotype. The highly satiating diet also favoured an exceptionally good adherence rate and, despite higher body fat loss, was not associated with more important changes in eating behaviour traits in obese individuals compared with a control diet based on general healthy eating guidelines. These results suggest that a non-restrictive satiating diet is useful to improve body composition and satiety responsiveness in LSP and HSP individuals. More studies are needed to assess the long-term effects of a non-restrictive highly satiating diet on weight maintenance in LSP individuals. 


\section{Acknowledgements}

The authors would like to thank Christian Couture for his important contribution to the statistical analyses and Shirin Panahi for English proofreading. A special thanks to the men who participated in the project.

This work was supported by the Canadian Institute of Health Research (A. T., grant no. MOP-68858). The Canadian Institute of Health Research had no role in the design, analysis or writing of this article.

V. D., A. T., J.-P. D., D. R., B. L. and J. E. B. formulated the research question, conceived the study design and obtained funding for the study. V. D. supervised the study. H. A. and V. D. contributed to the statistical analyses and H. A. drafted the manuscript. All authors participated in data interpretation, critically reviewed the manuscript and approved the final version.

The authors have no potential conflicts of interests to disclose.

\section{References}

1. Hopkins M \& Blundell JE (2016) Energy balance, body composition, sedentariness and appetite regulation: pathways to obesity. Clin Sci 130, 1615-1628.

2. Barkeling B, King NA, Näslund E, et al. (2007) Characterization of obese individuals who claim to detect no relationship between their eating pattern and sensations of hunger or fullness. Int J Obes 31, 435-439.

3. Drapeau V, Hetherington M \& Tremblay A (2011) Impact of eating and lifestyle behaviours on body weight. Beyond energy value. In Handbook of Behaviour, Diet and Nutrition Vol. Part 5, pp. 693-706 [VR Preedy, R Ross Watson and CR Martin, editors]. New York: Springer.

4. Drapeau V, Blundell J, Therrien F, et al. (2005) Appetite sensations as a marker of overall intake. BrJ Nutr 93, 273-280.

5. Drapeau V, King N, Hetherington M, et al. (2007) Appetite sensations and satiety quotient: predictors of energy intake and weight loss. Appetite 48, 159-166.

6. Drapeau V, Blundell J, Gallant AR, et al. (2013) Behavioural and metabolic characterisation of the low satiety phenotype. Appetite 70, 67-72.

7. Langeveld M \& DeVries JH (2015) The long-term effect of energy restricted diets for treating obesity: effect of diets for treating obesity. Obesity 23, 1529-1538.

8. Gilbert J-A, Joanisse DR, Chaput J-P, et al. (2011) Milk supplementation facilitates appetite control in obese women during weight loss: a randomised, single-blind, placebocontrolled trial. Br J Nutr 105, 133-143.

9. Rolls BJ (2009) The relationship between dietary energy density and energy intake. Physiol Behav 97, 609-615.

10. Anderson GH \& Moore SE (2004) Dietary proteins in the regulation of food intake and body weight in humans. $J$ Nutr 134, 974S-979S.

11. Halton TL \& Hu FB (2004) The effects of high protein diets on thermogenesis, satiety and weight loss: a critical review. J Am Coll Nutr 23, 373-385.

12. Dahl WJ \& Stewart ML (2015) Position of the Academy of Nutrition and Dietetics: Health Implications of Dietary Fiber. J Acad Nutr Diet 115, 1861-1870.

13. Parra D, Ramel A, Bandarra N, et al. (2008) A diet rich in long chain omega-3 fatty acids modulates satiety in overweight and obese volunteers during weight loss. Appetite 51, 676-680.

14. Gonzalez JT, Green BP, Brown MA, et al. (2015) Calcium ingestion suppresses appetite and produces acute overcompensation of energy intake independent of protein in healthy adults. $J$ Nutr 145, 476-482.

15. Tremblay A, Arguin H \& Panahi S (2016) Capsaicinoids: a spicy solution to the management of obesity? Int J Obes $\mathbf{4 0}$, 1198-1204.

16. Health Canada (2007) Eating well with Canada's food guide. http://www.hc-sc.gc.ca/fn-an/food-guide-aliment/index-eng.php (accessed March 2017).

17. Stunkard AJ \& Messick S (1985) The three-factor eating questionnaire to measure dietary restraint, disinhibition and hunger. J Psychosom Res 29, 71-83.

18. Hill A \& Blundell J (1986) Macronutrients and satiety: the effects of a high-protein or high-carbohydrate meal on subjective motivation to eat and food preferences. Nutr Behav 3, 133-144.

19. Arvaniti K, Richard D \& Tremblay A (2000) Reproducibility of energy and macronutrient intake and related substrate oxidation rates in a buffet-type meal. Br J Nutr 83, 489-495.

20. Dalton M, Hollingworth S, Blundell J, et al. (2015) Weak Satiety responsiveness is a reliable trait associated with hedonic risk factors for overeating among women. Nutrients 7, 7421-7436.

21. The Airlie (VA) Consensus Conference (1988) Part 1. Measurement descriptions and techniques. In Anthropometric Standardization Reference Manual, pp. 39-80 [TG Lohman, AF Roche and R Martorell, editors]. Champaign, IL: Human Kinetics Publishers.

22. Westenhoefer J, Stunkard AJ \& Pudel V (1999) Validation of the flexible and rigid control dimensions of dietary restraint. Int J Eat Disord 26, 53-64.

23. Laessle RG, Tuschl RJ, Kotthaus BC, et al. (1989) A comparison of the validity of three scales for the assessment of dietary restraint. J Abnorm Psychol 98, 504-507.

24. Lluch A (1995) Identification des conduites alimentaires par approches nutritionnelles et psychométriques: implications thérapeutiques et préventives dans l'obésité humaine (Identification of food intake behaviours by nutritional and psychometrics means: implications for prevention and treatment of human obesity). PhD Thesis, University of Nancy.

25. Foster-Powell K, Holt SHA \& Brand-Miller JC (2002) International table of glycemic index and glycemic load values: 2002. Am J Clin Nutr 76, 5-56.

26. Poortvliet PC, Bérubé-Parent S, Drapeau V, et al. (2007) Effects of a healthy meal course on spontaneous energy intake, satiety and palatability. Br J Nutr 97, 584.

27. Brown JD, Buscemi J, Milsom V, et al. (2016) Effects on cardiovascular risk factors of weight losses limited to 5-10\%. Transl Behav Med 6, 339-346.

28. Villeneuve N, Pelletier-Beaumont E, Nazare J-A, et al. (2014) Interrelationships between changes in anthropometric variables and computed tomography indices of abdominal fat distribution in response to a 1 -year physical activity-healthy eating lifestyle modification program in abdominally obese men. Appl Physiol Nutr Metab 39, 503-511.

29. Despres J-P, Lemieux I, Bergeron J, et al. (2008) Abdominal obesity and the metabolic syndrome: contribution to global cardiometabolic risk. Arterioscler Thromb Vasc Biol 28, 1039-1049.

30. Leidy HJ, Carnell NS, Mattes RD, et al. (2007) Higher protein intake preserves lean mass and satiety with weight loss in preobese and obese women. Obesity 15, 421-429.

31. Tang M, Armstrong CLH, Leidy HJ, et al. (2013) Normal vs. high-protein weight loss diets in men: effects on body composition and indices of metabolic syndrome. Obesity (Silver Spring) 21, E204-E210.

32. Wycherley TP, Moran LJ, Clifton PM, et al. (2012) Effects of energy-restricted high-protein, low-fat compared with standard-protein, low-fat diets: a meta-analysis of randomized controlled trials. Am J Clin Nutr 96, 1281-1298. 
33. Gilbert J-A, Drapeau V, Astrup A, et al. (2009) Relationship between diet-induced changes in body fat and appetite sensations in women. Appetite 52, 809-812.

34. Flood JE \& Rolls BJ (2007) Soup preloads in a variety of forms reduce meal energy intake. Appetite 49, 626-634.

35. Rolls BJ, Roe LS \& Meengs JS (2004) Salad and satiety: energy density and portion size of a first-course salad affect energy intake at lunch. J Am Diet Assoc 104, 1570-1576.

36. Williams RA, Roe LS \& Rolls BJ (2014) Assessment of satiety depends on the energy density and portion size of the test meal. Obesity (Silver Spring) 22, 318-324.

37. Pérez-Escamilla R, Obbagy JE, Altman JM, et al. (2012) Dietary energy density and body weight in adults and children: a systematic review. J Acad Nutr Diet 112, 671-684.

38. Williams RA, Roe LS \& Rolls BJ (2013) Comparison of three methods to reduce energy density. Effects on daily energy intake. Appetite 66, 75-83.

39. Arguin H, Gagnon-Sweeney M, Pigeon É, et al. (2012) Functional food and satiety. Impact of a satiating context effect on appetite control of non-obese men. Appetite 58, 354-363.

40. Clifton PM, Keogh JB \& Noakes M (2008) Long-term effects of a high-protein weight-loss diet. Am J Clin Nutr 87, 23-29.

41. Yang D, Liu Z, Yang H, et al. (2014) Acute effects of highprotein versus normal-protein isocaloric meals on satiety and ghrelin. Eur J Nutr 53, 493-500.

42. Larsen TM, Dalskov S-M, van Baak M, et al. (2010) Diets with high or low protein content and glycemic index for weightloss maintenance. $N$ Engl J Med 363, 2102-2113.

43. Mikkelsen PB, Toubro S \& Astrup A (2000) Effect of fatreduced diets on 24-h energy expenditure: comparisons between animal protein, vegetable protein, and carbohydrate. Am J Clin Nutr 72, 1135-1141.

44. Martens EAP \& Westerterp-Plantenga MS (2014) Protein diets, body weight loss and weight maintenance. Curr Opin Clin Nutr Metab Care 17, 75-79.

45. Veldhorst M, Smeets A, Soenen S, et al. (2008) Proteininduced satiety: effects and mechanisms of different proteins. Physiol Behav 94, 300-307.

46. Krog-Mikkelsen I, Sloth B, Dimitrov D, et al. (2011) A low glycemic index diet does not affect postprandial energy metabolism but decreases postprandial insulinemia and increases fullness ratings in healthy women. J Nutr 141, 1679-1684.

47. Roberts SB (2003) Glycemic index and satiety. Nutr Clin Care 6, 20-26.

48. Carreiro AL, Dhillon J, Gordon S, et al. (2016) The macronutrients, appetite, and energy intake. Annu Rev Nutr 36, 73-103.
49. Ye EQ, Chacko SA, Chou EL, et al. (2012) Greater whole-grain intake is associated with lower risk of type 2 diabetes, cardiovascular disease, and weight gain. J Nutr 142, 1304-1313.

50. Wanders AJ, van den Borne JJGC, de Graaf C, et al. (2011) Effects of dietary fibre on subjective appetite, energy intake and body weight: a systematic review of randomized controlled trials: dietary fibres, appetite and body weight. Obes Rev 12, 724-739.

51. Blundell JE \& Halford JC (1994) Regulation of nutrient supply: the brain and appetite control. Proc Nutr Soc 53, 407-418.

52. de Graaf C, Blom WAM, Smeets PAM, et al. (2004) Biomarkers of satiation and satiety. Am J Clin Nutr 79, 946-961.

53. Golub N, Geba D, Mousa SA, et al. (2011) Greasing the wheels of managing overweight and obesity with omega- 3 fatty acids. Med Hypotheses 77, 1114-1120.

54. Chambers L, McCrickerd K \& Yeomans MR (2015) Optimising foods for satiety. Trends Food Sci Technol 41, 149-160.

55. Bryant EJ, King NA \& Blundell JE (2007) Disinhibition: its effects on appetite and weight regulation: disinhibition's effects on weight regulation. Obes Rev 9, 409-419.

56. Ouwens MA, van Strien T \& van der Staak CPF (2003) Tendency toward overeating and restraint as predictors of food consumption. Appetite 40, 291-298.

57. Carr KA, Lin H, Fletcher KD, et al. (2014) Food reinforcement, dietary disinhibition and weight gain in nonobese adults. Obesity (Silver Spring) 22, 254-259.

58. Rogers M, Lemstra M, Bird Y, et al. (2016) Weight-loss intervention adherence and factors promoting adherence: a meta-analysis. Patient Prefer Adherence 10, 1547-1559.

59. Johnston BC, Kanters S, Bandayrel K, et al. (2014) Comparison of weight loss among named diet programs in overweight and obese adults: a meta-analysis. JAMA 312, 923.

60. Meule A, Westenhöfer J \& Kübler A (2011) Food cravings mediate the relationship between rigid, but not flexible control of eating behavior and dieting success. Appetite 57, 582-584.

61. Atkinson G \& Batterham AM (2015) True and false interindividual differences in the physiological response to an intervention. Exp Physiol 100, 577-588.

62. Bayer O, Krüger H, von Kries R, et al. (2011) Factors associated with tracking of BMI: a meta-regression analysis on BMI tracking. Obesity (Silver Spring) 19, 1069-1076.

63. Atkinson G \& Nevill AM (1998) Statistical methods for assessing measurement error (reliability) in variables relevant to sports medicine. Sports Med 26, 217-238. 